\title{
The Application of Project - driven Teaching Method in the Teaching of Postgraduates' Dialectology
}

\author{
Shiliang Lyu ${ }^{1, a}$ \\ ${ }^{1}$ Key Laboratory of National Language Intelligent Processing, Gansu Province, Northwest MinZu \\ University, Lanzhou, China \\ ashilianglv@126.com
}

Keywords: Dialectology; Project-driven teaching method; Teaching reform; Teaching methods

\begin{abstract}
Dialectology is often used as a compulsory or elective course in postgraduate teaching. It is an important course in the curriculum system of linguistics students. Project-driven teaching method is a constructivist teaching method by creating a simulation project context. This paper combines the linguistics and applied linguistics graduate of Northwest MinZu University, from the actual conditions of teaching and scientific research. Discusses the specific project design of the project-driven teaching method in the teaching of graduate dialectology, and also points out the problems that need attention.
\end{abstract}

\section{Research Background}

As a branch of linguistics, dialectology is a course for postgraduates majoring in Linguistics and Applied Linguistics. As an important basic course of linguistics and applied linguistics, dialectology is of great significance to guide students to study linguistic theory, improve the level of language research and study the development and evolution of speech [1]. This paper studies the reform methods of the course system of dialectology, highlight the interdisciplinary study of linguistics, so that linguistics and applied linguistics students based on dialectology and master the new method of language research. It also has practical significance to strengthen students' practice and innovation ability.

The dialectology offered by postgraduate students of Linguistics and Applied Linguistics in Northwest University for Nationalities at the initial stage. Due to the influence of students' research orientation and undergraduate majors, the teaching content should be properly allocated according to the actual situation of students. And linguistics and applied linguistics is a new discipline, which is different from traditional linguistics and has an interdisciplinary nature. The same is true of dialect research, which is to study the interdisciplinary thinking through language research and propose new ideas and methods for language research. In the process of dialectology teaching in Northwest MinZu University, it should be combined with the advantages of ethnic language, learn from interdisciplinary language research methods, and broaden the innovative ideas in the course of dialectology. In the teaching process to implement the project-driven teaching method, reform the curriculum system at the same time improve the teaching effect.

\section{The Implementation of Project - Driven Teaching Method}

Project-driven teaching method is the use of real or virtual project context set of teaching tasks, is based on structuralist learning theory derived from a teaching method. Students do not need the teacher's instruction in the process of acquiring knowledge, mainly through the specific auxiliary situation, access to the necessary information from the Self-regulated learning to obtain knowledge [2]. Graduate teaching is different from undergraduate, should pay more attention to the cultivation of students' self-learning and research ability. The use of project-driven teaching methods is more helpful in stimulating students' curiosity and learning interest. While teaching knowledge, the teacher arranges students' dialect learning tasks, requires them to learn and solve puzzles independently, and finally achieves the expected mission goal.

The teacher mainly plays an auxiliary role in the whole process to solve the key and difficult 
problems in the dialect courses, and summarize the new knowledge. Such as the combination of experimental dialectology, dialect geography and other new areas of research. Teachers based on the teaching content of the research project layout, combined with new areas of dialect research, to encourage students to expand the research perspective, and carry out project research in depth. The adoption of project-driven teaching methods is more conducive to cultivating students' practical innovation ability while researching independently.

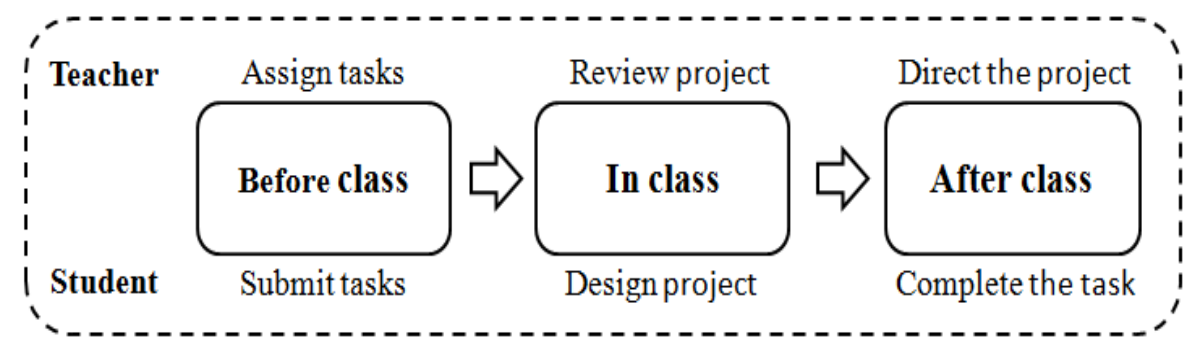

Figure 1. Finite Project - driven teaching method implementation process

Graduate teaching is different from undergraduate teaching. The graduate teaching pay more attention to self-learning and research ability training, the most important thing is to determine the learning objectives. In the project-driven, first teaching should be centered on students, and students should be fully considered when designing projects. In the whole process, teachers should aim at improving the students' research level, design suitable teaching activities for students, and organize students to participate in the project. Before the class, the teacher should assign the teaching task, the student to submit the completed tasks. During the course of the class, the teacher reviews the tasks completed and the students begin the new task flow according to the assigned tasks. The teacher instructs the student project after class, and the student completes the study task under the guidance of the teacher (refer with: Fig. 1).

Before the project starts, the teacher needs to lay out the details of the student tasks and set the goals for the project. It is often possible to design the research scheme of dialect, to assign students to the unit and assign tasks to different students. During the whole process of the project, teachers also guide students to think and solve problems, improve the ability of students to deal with and solve problems. In the process of teachers' macro-control of the whole project, the progress of the project is closely related to the tasks of the students, which is beneficial to the evaluation of the accomplishment of the student's task.

\section{Project Design of Project - Driven Teaching Method in Dialectology Course}

The course of dialect learning of Northwest MinZu University is based on many years of research, which is aimed at students' basic and research direction, in order to make up for the students' basic theoretical knowledge for the purpose of opening courses. The main contents of the dialectology course are the basic knowledge of Chinese dialect and the basic knowledge of phonology, but also the language differences of dialects in ethnic language [3]. For example, three Tibetan Dialects: linguistic differences between Lhasa dialect, Kangba dialect and Amdo dialect. In terms of Chinese dialects, it mainly deals with the development and evolution of the seven dialects of Chinese: northern dialect, Wu dialect, Hunan dialect, Gan dialect, Hakka dialect, Guangdong dialect and min dialect [4].

In the process of teaching, according to the previous teaching experience, teaching contents of comprehensive dialectology and other disciplines of linguistics. Using project-driven teaching methods suitable for linguistics and applied linguistics students. In the prerequisite course, the linguistic theory course is based on all the languages of the world. Linguistic theory emphasizes the most basic and common rules of language. 


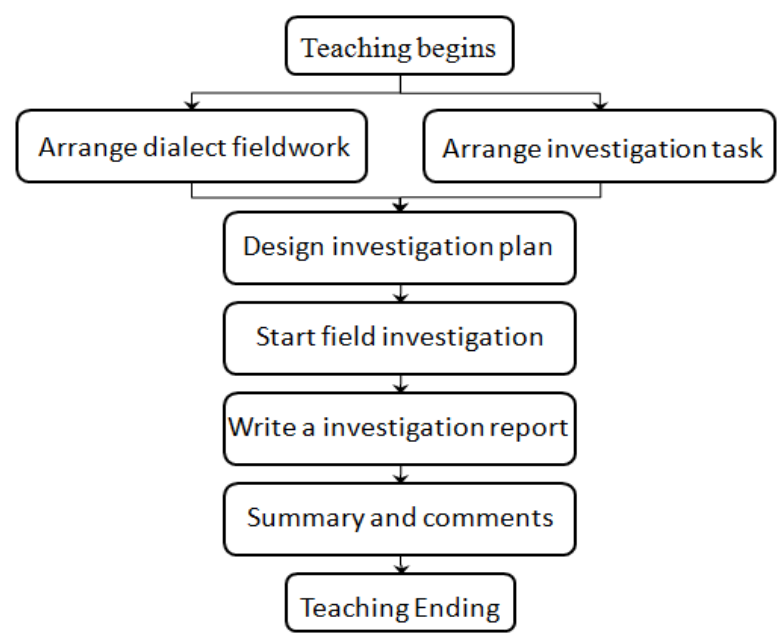

Figure 2. Finite Dialectology course project-driven instructional design process

The teaching content of linguistic theory plays an important role in the course of linguistics. The teaching contents of the introduction to linguistics are both the promotion of the teaching theory of dialectology teaching and the principle of instructing the content of dialect teaching. In the teaching process, at the same time of summing up experience, let the students to fully grasp the linguistic theories knowledge. Then, on the basis of Chinese dialectology and linguistics which has been mastered, the project-driven teaching method is used to enable students to obtain comprehensive analysis of problems and solve problems, so that students have a more rational understanding of theoretical knowledge.

The biggest difference between dialects is the difference in speech, learning dialect theory and research dialects first to master the field survey method, through the field investigation to understand the real situation of dialect pronunciation [5]. At present, the field of dialect research mainly focuses on the geographical distribution of dialects, the historical sources of dialects, experimental dialects and social dialects, etc. Fieldwork is a necessary way to obtain first-hand knowledge of dialects [6]. Project design is the key to the implementation of project - driven teaching method(refer with: Fig. 2). When carrying out project-driven teaching, the project of dialect survey is first assigned, and the relevant tasks of field survey are arranged. The students design the survey plan according to the project arrangement. The students then carry out dialect fieldwork in the way of autonomous learning and collaborative tasks, and teachers will guide them during the process of investigation. After the completion of the field investigation, carry out the task link of the investigation report. Finally, the teacher summarizes and reviews the project and completes the project-driven teaching process.

\section{Problems Needing Attention in Teaching}

The research methods in dialectology are a comprehensive training and test of knowledge and skills for language researchers. Whether it is a study of dialectology courses or investigators of dialects are inseparable from the fieldwork. After learning the theoretical knowledge in the classroom, through the practice of the field, it is more conducive to the cultivation of students' practical ability. During the implementation of project-driven teaching process, teaching tasks and fieldwork should be combined. In particular, the postgraduate dialectology courses should be arranged in practice in addition to the classroom teaching, so as to cultivate students' practical ability in fieldwork. Moreover, in the process of guiding the implementation of tasks, teachers should combine theoretical knowledge with practice according to the students' learning situation.

Fieldwork in dialect study, through field investigation to obtain first-hand information, especially on the dialect of initials, finals and tones system have great effect, is also the most effective way to obtain dialect phonetic overall appearance. After the completion of the project, the evaluation link of the teacher is very important. At the completion of the project, the evaluation mode is different 
from the traditional teaching method. It is necessary to pay attention to the evaluation methods in the implementation of the driving teaching of dialect, and generally divide the evaluation into two parts: theory and practice. It is also necessary to evaluate the students' ability to independently learn and collaborate in the project.

\section{Summary}

Through the course system reform, strengthen the investigation method of dialect. Fieldwork is the premise of acquiring a large number of objective and authentic corpus. Students' training through fieldwork is the premise of language research and work. It is also the most important method to improve the efficiency of language research. Using the project-driven teaching model to dialect research based on the survey method, so that students master dialect and national language and other language research programs and ideas.

The project-driven teaching mode is the reform of the traditional teaching mode. In the postgraduate dialect teaching, so that graduate students become the main learning, teachers in the project to guide all aspects of the link. Students are able to accomplish tasks through autonomous learning and collaborative learning, changing the traditional teaching mode to achieve better teaching results.

\section{Acknowledgements}

This research was financially supported by Graduate education and teaching reform research project of Northwest MinZu University

\section{Reference}

[1] Li Xiaofan, Xiang Mengbing. Basic Course of Chinese Dialectology. Peking University Press, 2009.

[2] Ma Lingling. An Empirical Study on Developing Students Autonamy Learning Ability through projec-Based Learning. Journal of Shanxi Radio\&TV University, 2010, 15 (2): 54-55.

[3] Liu zhenfa, li rulong. The significance of Chinese dialects in linguistics. Journal of shenzhen university (humanities and social sciences), 2003, 20 (4) : 104-109.

[4]Li Rong. Partition of Chinese dialects. Dialect, 1989 (4): 241-259.

[5] Pan Wuyun. Chinese dialectology and phonology research prospective. Journal of Jinan University (philosophical social science edition), 2005, 27 (5): 104-107.

[6] You Rujie. The tradition, modernization and development trend of Chinese dialects. Modern Chinese journal, 2007 (1) : 33-38. 